\title{
Research on the ecology of ticks and tick-borne pathogens - methodological principles and caveats
}

\author{
${ }^{1}$ Faculty of Veterinary Medicine, Department of Animal Pathology, University of Zaragoza, Zaragoza, Spain \\ 2 UCD School of Biology and Environmental Science, University College Dublin, Dublin, Ireland \\ 3 Tick-radar GmbH, Berlin, Germany \\ ${ }^{4}$ Department of Environmental Science, Policy and Management, University of California, Berkeley, USA \\ ${ }^{5}$ Institute for Parasitology and Tropical Veterinary Medicine, Freie Universität Berlin, Berlin, Germany
}

Agustín Estrada-Peña ${ }^{1 *}$, Jeremy S. Gray ${ }^{2}$, Olaf Kahl ${ }^{3}$, Robert S. Lane ${ }^{4}$ and Ard M. Nijhof

\section{Edited by:}

Jose De La Fuente, Instituto de

Investigación en Recursos

Cinegéticos, Spain

\section{Reviewed by:}

Jose De La Fuente, Instituto de Investigación en Recursos

Cinegéticos, Spain

Francisco Ruiz-Fons, Spanish

National Wildlife Research Institute

(IREC); Spanish Research Council,

Spain

*Correspondence:

Agustín Estrada-Peña, Faculty of Veterinary Medicine, Department of Animal Pathology, University of Zaragoza, Miguel Servet, 177.

50013-Zaragoza, Spain

e-mail: aestrada@unizar.es
Interest in tick-transmitted pathogens has experienced an upsurge in the past few decades. Routine application of tools for the detection of fragments of foreign DNA in ticks, together with a high degree of interest in the quantification of disease risk for humans, has led to a marked increase in the number of reports on the eco-epidemiology of tick-borne diseases. However, procedural errors continue to accumulate in the scientific literature, resulting in misleading information. For example, unreliable identification of ticks and pathogens, erroneous interpretations of short-term field studies, and the hasty acceptance of some tick species as vectors have led to ambiguities regarding the vector role of these arthropods. In this review, we focus on the ecological features driving the life cycle of ticks and the resulting effects on the eco-epidemiology of tick-transmitted pathogens. We review the factors affecting field collections of ticks, and we describe the biologically and ecologically appropriate procedures for describing tick host-seeking activity and its correlation with environmental traits. We detail the climatic variables that have biological importance on ticks and explain how they should be properly measured and analyzed. We also provide evidence to critically reject the use of some environmental traits that are being increasingly reported as the drivers of the behavior of ticks. With the aim of standardization, we propose unambiguous definitions of the status of hosts and ticks regarding their ability to maintain and spread a given pathogen. We also describe laboratory procedures and standards for evaluating the vectorial capacity of a tick or the reservoir role of a host. This approach should provide a coherent framework for the reporting of research findings concerning ticks and tick-borne diseases.

Keywords: ticks, tick-transmitted pathogens, methodological gaps, protocols, interpretations

\section{INTRODUCTION}

Ticks are fascinating vectors of many pathogens affecting human and animal health, and research on this topic was boosted by the emergence of the zoonotic tick-borne disease, Lyme borreliosis, three decades ago (Ostfeld et al., 2005). The discovery of formerly unknown mechanisms of pathogen transmission, such as the non-viremic transmission of TBE virus (Labuda et al., 1993), and the re-emergence of certain tick-borne diseases, such as the ongoing epidemic of Crimean-Congo hemorrhagic fever in Turkey, likewise have created a wealth of research interest (Gale et al., 2010).

The adoption of DNA detection as a general tool during the 1990s to investigate the relationships between ticks, ticktransmitted pathogens and their vertebrate hosts further accelerated interest in the field. However, this has resulted in much misinterpretation of the vectorial capacity of ticks and the reservoir competence of vertebrates. A review of digital bibliographical databases for the period 2000-2010 revealed 512 papers dealing with ticks and transmitted pathogens in Europe alone (Estrada-Peña et al., 2013). Of these, 311 reported associations and relationships between tick and pathogens, at different scales (local, regional, or national). Further, 109 reports in that period dealt with newly determined associations between pathogens and ticks collected while feeding on a host. As noted by Kahl et al. (2002) "partially or fully-fed ticks removed from hosts that contain [pathogens] may or may not be vectors because nearly all hematophagous arthropods feeding on reservoir hosts are likely to ingest some microorganisms with the blood meal." Such reporting of crude associations between pathogens and engorged ticks has only served to confuse our understanding of the relationships between ticks, tick hosts and tick-transmitted pathogens.

A later surge in interest in ticks and tick-borne pathogens has been inspired by recent claims about the impact of forecasted climate change on the spatial distribution of ticks and associated pathogens (Brownstein et al., 2003; Ostfeld et al., 2005; DiukWasser et al., 2006; Ogden et al., 2008; Jaenson et al., 2009). However, this research has been fraught with difficulty from the outset because of insufficient knowledge about the nature of many tick-pathogen associations (Randolph, 2009; Franke et al., 2013; Medlock et al., 2013). A proper understanding of how 
abiotic factors shape the transmission cycles of tick-transmitted disease agents awaits a more rigorous analysis that is often limited by the current availability of data and the many indirect mechanisms that bear on them (Kahl et al., 2002; Eisen, 2008).

We assume that the many procedural and analytical errors in current tick and tick-borne zoonotic disease research are often a consequence of a lack of knowledge or of suitable training. This paper is not intended as an exhaustive review on tick biology and behavioral ecology, but a summary of existing knowledge regarding the processes involved in planning surveys, the collection of field data, and the relationships of ticks with abiotic variables. We have paid special attention to the variables regulating the activity of the ticks, and how these should be recorded and interpreted. Further, we discuss the need to standardize the eco-epidemiological terminology of ticks, hosts, and pathogens, as already discussed by Kahl et al. (2002) among others. We focus on exophilic ixodid ticks, which are those that develop on the ground, without needing to shelter in burrows or nests of their vertebrate hosts (such ticks are referred to as endophilic).

\section{OVERVIEW}

Figure 1 summarizes the flow of information and critical points in the collection of ticks, and the determinations and interpretations of relationships between ticks and microorganisms, which we will address in this review. The three key elements in this ecological system, namely the ticks, the hosts, and the tick-transmitted pathogens are impacted directly or indirectly by abiotic and biotic factors. We will review what specific combinations of abiotic factors activate ticks, and how to collect questing ticks to minimize sampling bias and maximize the robustness of the resultant data. We further review how to correlate weather variables with empirical data on ticks. At each stage of the surveys, accurate identification of ticks, their vertebrate hosts and associated microorganisms is critical, because errors would lead to reports of unusual associations of vertebrates, pathogens and ticks. Every tick specimen should be identified with reliable keys and compared with voucher reference specimens when necessary, before extracting their DNA for molecular analyses. In the same way, the lack of reliable identification of the hosts, or the erroneous detection of host DNA in the blood-meal remnants in the tick, might prevent accurate determination of the associations between the three partners. In the case of pathogen detection, polymerase chain reaction (PCR) and other molecular assays must be done in strict accordance with good laboratory practices (GLPs) and must include positive and negative controls with each run.

The importance of laboratory work is also shown in Figure 1. While the prevalence of a given pathogen may be calculated from field collections of unfed ticks, the vector status of the tick cannot be determined from such data alone. Additional vector and reservoir competence studies must be carried out in the laboratory before it can be concluded that a particular tick is a vector, or a host is a reservoir of a pathogen. We elaborate on these concepts in a later section of this review.

\section{THE COLLECTION OF OUESTING TICKS}

A critical initial step in studies on ticks and associated pathogens is the collection of the ticks, which, for the production of reliable results, should adhere to a series of principles. The abundance of ticks can be estimated either by surveying the hosts on which ticks feed or by sampling low vegetation or leaf-litter areas at defined intervals and periods of time. A rough estimation of the density of questing ticks can be obtained by sampling questing ticks from the vegetation and from the leaf litter (TälleklintEisen and Lane, 2000b). Additionally, this approach can also be used to procure ticks for testing for zoonotic agents. Questing is the process in the life cycle of ticks in which they actively seek a host. The span and the intensity of the periods of questing,

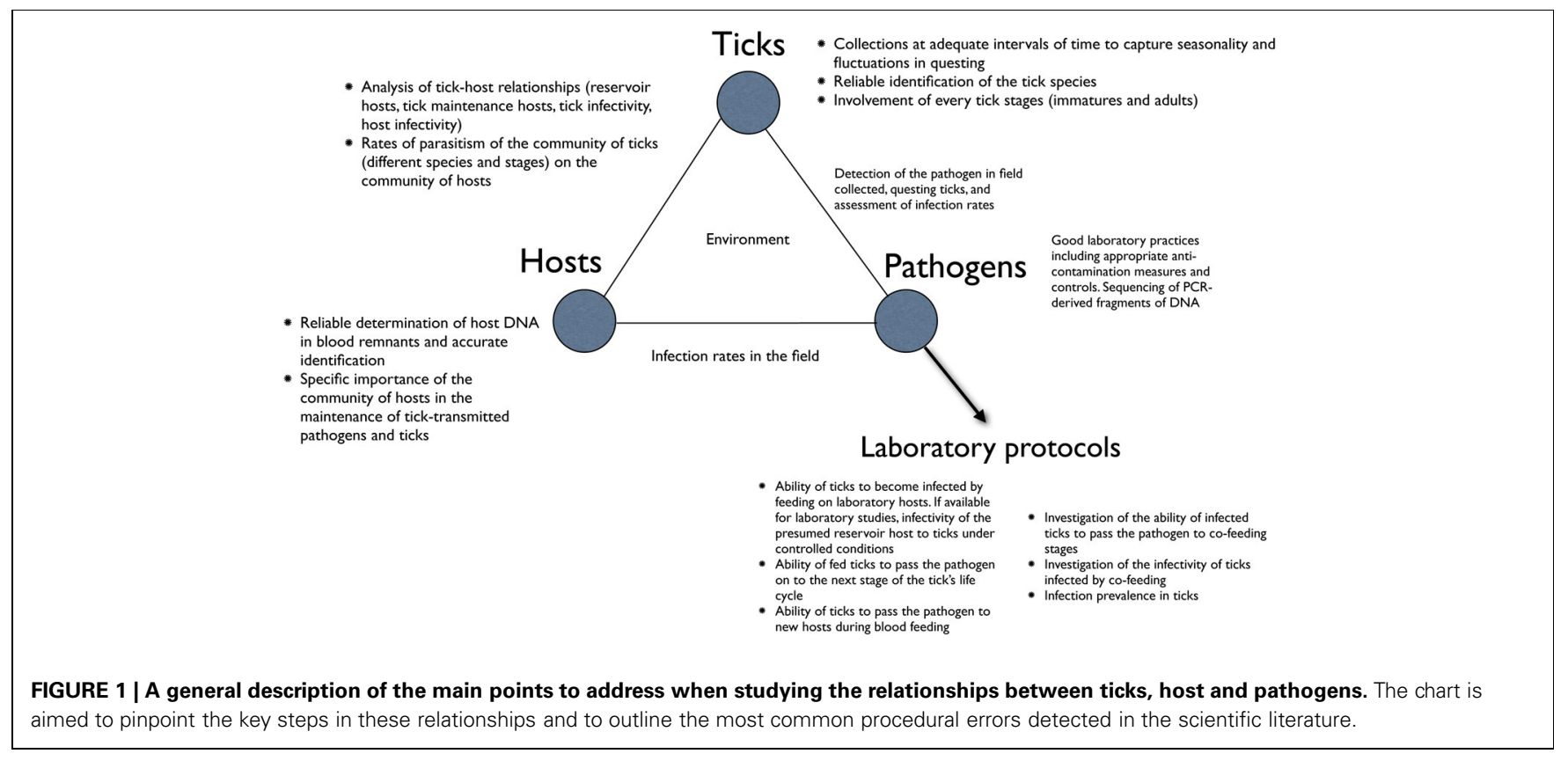


and even the simultaneous questing of different stages of the same species, may have profound epidemiological implications for the epidemiology of particular tick-transmitted pathogens (Randolph, 2000). By adequately recording the changing abundance of questing ticks, the response of a species to weather traits can be estimated, and their geographical or seasonal changes, tracked.

The common procedure for collections of questing ticks is by dragging a piece of fabric such as flannelette or blanket across the vegetation surface or over the leaf litter. These can either be large pieces of fabric dragged behind the operator, or more commonly are relatively small pieces $\left(1 \mathrm{~m}^{2}\right)$ mounted on poles and brushed over the vegetation, a procedure known as "flagging." Many operators compromise between these two approaches. The ticks adhering to the fabric are collected at varying intervals, but it should be borne in mind that prolonged dragging distances result in a loss of ticks (see below). Flagging (or dragging) can provide an estimate of the rates of tick activity, which are characterized by several cycles of ascending and descending movements of the ticks in the vegetation. It is necessary to follow some basic rules in order to obtain an accurate representation of the questing activity, so that comparisons may be made with data from different sites, periods of time and from other studies, and to associate the observed questing rates with abiotic features (e.g., weather). Sampling must be conducted over homogeneous patches of vegetation, but a stratified sampling approach may be adopted to obtain a reliable representation of questing ticks in a given area. Vegetation cover affects the efficiency of the flagging or dragging method and heterogeneously modifies the micro-climate at the level where the ticks quest, thereby affecting their behavior and their observed abundance (Tälleklint-Eisen and Lane, 2000b). It also affects the abundance of hosts, and this may influence the perceived abundance of ticks, at the scale of small patches of vegetation. Tick abundance may vary significantly by aspect (exposure, such as south-facing) in hilly or mountainous areas (Lane et al., 1985).

To determine tick density (abundance per unit area) it is necessary to walk slowly over a defined distance. In some sites it is impossible to obtain sufficient uniformity for area-based dragging, and a time-based approach is indicated (e.g., number per hour) with adequate standardization. There are no rules regarding the overall length of a transect, but small ones $(<100 \mathrm{~m})$ may adversely affect the reliability of the results, since the spatial distribution of ticks is usually highly aggregated, even at sites where weather conditions and vegetation appear to be homogeneous (Wilson, 1998; Tälleklint-Eisen and Lane, 1999; Randolph, 2000). For each transect the operator must stop frequently enough (e.g., every $10 \mathrm{~m}$ ) to remove ticks from the flag or drag otherwise too many ticks will be dislodged by the substrate. Sites with a high density of ticks demand more frequent removal of ticks from the fabric. The results should preferably be expressed as the number of ticks per unit area, but occasionally sites are too difficult to sample in this manner and in these cases a standardized time-based approach may be used (Gray et al., 1992). It also should be borne in mind that only a relatively small proportion of the total population of ticks in a given area may be questing simultaneously.
The questing activity of some ticks cannot be determined by dragging. For example, the immatures of some species of Dermacentor, Rhipicephalus, and Hyalomma are mainly endophilic, living inside the burrows of their hosts (Salman and Estrada-Peña, 2013). This also applies to certain species in the genus Ixodes that are nidicolous (Filippova, 1977; Lane et al., 1999). The only way to evaluate the seasonality of endophilic ticks is by direct sampling of the nesting materials or the burrows of their hosts or the primary hosts themselves (Vial, 2009). Moreover, the adults of the genera Amblyomma and Hyalomma are not collected homogeneously by dragging, because they have a "hunter" strategy to find a host. These ticks tend to shelter in litter areas to escape from desiccating microclimate conditions, and although they may be collected by dragging, this method is inefficient for such species. A survey should involve at least two or three consecutive years of sampling at relatively short intervals of time to be meaningful, preferable at 7-10 day intervals. Budgetary or other constraints may render this difficult, but relatively infrequent sampling (e.g., monthly intervals) fail to capture the seasonality of most tick species as well as the influence of abiotic factors on questing.

Quantitative terms regarding questing ticks have been reviewed previously (Wilson, 1994; Kahl et al., 2002). The abundance of questing ticks is a dimensionless measure, whereas density is a description of the number of ticks collected per unit area or time (Kahl et al., 2002). It is a mistake to interpret the number of questing ticks collected in field surveys as a measure of the total number of ticks in an area (Tälleklint-Eisen and Lane, 2000a,b).

Another method to obtain estimates of relative tick abundance is sampling from hosts. Ideally sentinel domestic animals such as sheep should be used in defined areas, but this is not often possible and most data sets consist of samples from domestic animals in relatively uncontrolled circumstances, from trapped rodents or birds and from wild ungulates at hunting points. Complete data sets are usually not possible because of the preferences of different tick stages for certain host species. Another drawback of this approach may be the fluctuations of host abundance, usually outside the control of the investigator that affect the intensity of tick infestations. However, compared with the sampling of ticks from the vegetation and leaf litter, data from animals are not so affected by short-term variables such as weather or from factors that can distort the data such as the structure of vegetation. When ticks are collected from hosts, the prevalence of infestation describes the percentage of hosts examined and found infested. The mean density of ticks per host is calculated as the total number of ticks obtained, divided by the total number of hosts examined. The intensity of infestation is the total number of ticks observed divided by the number of infested hosts (Kahl et al., 2002).

\section{RELATING THE PHENOLOGY OF TICKS TO ENVIRONMENTAL (ABIOTIC) FEATURES}

Tick researchers have been interested in discovering what abiotic factors drive the biology of ticks. The potential exists of evaluating seasonal patterns of activity resulting from various combinations of climatic conditions and in thereby obtaining an estimation of "risk" in a climate change scenario (Mannelli et al., 2003). 
Many reports have correlated environmental traits with empirical data concerning the life cycle of several species of ticks. Results obtained so far confirm that the development and questing of I. ricinus (Lees and Milne, 1951; Gray, 1982, 1991; Perret et al., 2000, 2003, 2004; Randolph, 2002; Randolph et al., 2002; EstradaPeña et al., 2004), I. scapularis (Daniels et al., 1996; Lindsay et al., 1999; Ogden et al., 2008), I. pacificus (Padgett and Lane, 2001), A. americanum (Schulze et al., 2001), R. appendiculatus (Randolph, 1993, 1997), Hyalomma spp. and Rhipicephalus spp. (Petney et al., 1987; Pegram and Banda, 1990), among others, are regulated by weather. It is, however, necessary to understand how the ticks become active before constructing guidelines for evaluating their patterns of activity.

Most ixodid ticks are inactive in the lowest layers of vegetation or in the leaf litter or soil before they begin to quest. A notable exception are the subadults of I. scapularis, which nocturnally can locate and attach to lizards sleeping in soil (Lane et al., 1995). The combination of a set of suitable conditions, which normally involves an activation temperature in the spring, triggers the activity causing the ticks to climb to the top of the vegetation to quest for hosts. During questing, ticks may lose water (Lees, 1946) that they normally regain by descending at intervals into the litter zone (Lees and Milne, 1951) where the ticks actively reabsorb water vapor from the atmosphere (Rudolph and Knülle, 1974; Kahl and Alidousti, 1997). After the ticks are rehydrated, they are ready to ascend the vegetation. Ticks vary in their ability to retain or to gain water (Kahl and Knülle, 1988) and there is an interspecific variability in the management of their water balance. Extrinsically, tick water balance is affected by the saturation deficit of water in the air (affecting water loss) and by relative humidity (affecting the possibility of water gain by active water vapor uptake), and, intrinsically, among other points, by the capability of ticks to find places with a favorable microclimate even when the weather is warm and dry, e.g., in the leaf litter. The energy reserves of the tick plus its ability to maintain an acceptable level of body water are the factors mainly regulating the short-term questing behavior of ticks. Host stimuli may also affect tick activity.

Tick questing activity in temperate regions follows a seasonal pattern with some short-term fluctuation largely depending on weather. Some species of ticks may have an almost uninterrupted process of parasitic and questing periods in tropical regions, because of the stable weather conditions (Belozerov and Kvitko, 1965). Besides weather or microclimate, photoperiod regulates tick seasonal periodicity by prevention (behavioral diapause in unfed ticks) or stimulation of questing activity in unfed specimens, or by interrupting development (morphogenetic or developmental diapause in engorged ticks). In both cases the inducing stimulus is the photoperiod, the day-night relative duration (or its change), which is perceived by ticks (Belozerov, 1982). These diapause mechanisms optimize the fate of a given population by enabling the ticks to find a host, to feed and to enter the molting period before the onset of adverse weather conditions such as winter. Although many studies and reviews have discussed how diapause determines the phenology of ticks (Gardiner and Gray, 1986; Pegram et al., 1988; Gray, 1991; Norval et al., 1991; Madder and Berkvens, 1997; Randolph, 1997), photoperiod is often ignored in studies on the seasonality of ticks.
Temperature is one of the main regulators of tick phenology. Only the temperature recorded between the litter and the height where ticks quest should be associated with the empirical data from field plots or dragging surveys. Other series of data, such as those recorded at stations used for climate recording, commonly placed at $2 \mathrm{~m}$ above the ground, are not suitable because they do not reflect the actual climate to which the ticks in the field site are exposed. There tends to be smaller variation of temperature and humidity at $2 \mathrm{~m}$ above the ground level than in the vegetation layer. The subtle variations of the microclimate experienced by the ticks will almost surely be lost in data series obtained from meteorological stations and possible correlations between weather and tick activity patterns are likely to be obscured. Ideally portable micro-loggers should be placed on the ground litter to record the weather at the sites where ticks develop and quest. A series of micro-loggers can also be placed at different heights above ground level to track changing conditions in microenvironments where the different tick stages quest.

Since parts of the seasonal tick activity pattern can be explained by responses to water loss, variables related to air humidity would probably show a regulatory action on the recorded phenology of questing ticks. It was demonstrated that the questing duration of nymphal I. ricinus is inversely related to the saturation deficit, whereas the duration of quiescence is not (Perret et al., 2003). The air water saturation deficit is the "drying power" of the air and is correlated with the losses of water by living tissues (Anderson, 1936). When environmental conditions are less desiccating, ticks will quest for longer periods. Abrupt declines in the proportion of questing ticks have been shown to coincide with abrupt increases in saturation deficit at field sites in Switzerland (Perret et al., 2000), the United Kingdom (Randolph et al., 2002) and Spain (Estrada-Peña et al., 2004). It is quite possible that other tick species exhibit similar behavior. It is important to note that relative humidity has a critical effect on the ability of ticks to absorb water. There is a critical equilibrium humidity above which ticks can actively absorb water and maintain their water balance (Knülle and Wharton, 1964) and survive for long time periods irrespective of the saturation deficit. Below this threshold of relative humidity, ticks cannot actively absorb water. Therefore, under conditions of low relative humidity, ticks cannot rehydrate even if the saturation deficit is low. However, under conditions of high relative humidity (e.g., $>85 \%$ in $I$. ricinus) ticks can actively take up water from air and saturation deficit may have a lesser role in the regulation of questing. This is a complex process because temperature, saturation deficit and relative humidity change on a diurnal basis.

Saturation deficit and relative humidity are not the same as rainfall, which is the trait commonly used to explain the course of tick questing activity or the mortality of questing or developing ticks. Patterns of precipitation undoubtedly have an effect on the relative humidity at the regional scale (Rao et al., 1996; Thornton et al., 2000). However, the effects are not the same in different biomes. There is no universal relationship between air humidity (or saturation deficit) and rainfall patterns. It is likely that analysis of rainfall as the only effective mechanism for the mortality or activity of ticks will produce poor correlations and erroneous conclusions. 


\section{CONFOUNDING FACTORS AND PROCEDURAL GAPS IN STUDIES OF TICK PHENOLOGY}

Multiple factors may affect the phenology of ticks, even if collections are carried out under a harmonized protocol as outlined above. Studies on the seasonality of ticks often correlate questing rates with the weather factors. However, an increase in questing rates may result from independent factors such as recruitment of newly molted ticks or resumption of activity during favorable weather conditions. A variable number of individuals may delay their onset of questing as a result of behavioral diapause (Gray, 1991), and older individuals may survive from previous periods of questing and overlap with later molted specimens. This could confound the correlation of the observed levels of activity with environmental factors. There is a lack of adequate studies regarding the effects of photoperiod on the induction of diapause and thus on tick seasonality (Gray, 2008). In fact, most recent research on seasonal activity has addressed only the presumed actions of either temperature or relative humidity.

One of the common ways to summarize tick questing activity is the clustering of observations by habitat type or plant alliances. The classification of the alliances of plant species into ecological categories is an old discipline that provides a homogeneous classification of the world biomes, which can then be correlated with weather traits and the characteristics of the soil (Menzel et al., 2006). Categories of vegetation are built on rules that summarize the dynamics of the plants and their response to the prevailing features of climate. These associations are in any case coarse in scale and the pattern emerges at national or continental scales. The association of the distribution patterns of ticks throughout the dominant biomes in large regions has been widely used to deal with otherwise confusing information about the distribution of ticks (Gilot et al., 1992, 1996). However, such correlations might give the false impression that the finely-tuned local processes of tick phenology are consistently correlated with simple categories of vegetation. Analyses of life cycle processes require linking the scales at which variation is measured to the scales at which the processes operate (Huston, 1999): The dominant vegetation influences occurrence, development and activity of ticks because it modulates the microclimate and because it affects the abundance of hosts. The actual driver of the processes is the microclimate, and the vegetation is only an indicator (Randolph and Storey, 1999). We advocate the description of patterns of presence and abundance of ticks as related to the vegetation only after understanding how local vegetation affects local microclimate and thus its indirect effects on the processes of tick life cycles. Otherwise, considerable information is lost in the process of clustering into categories of vegetation.

\section{IDENTIFICATION OF TICKS}

The importance of the correct identification of ticks is commonly underestimated. Without accurate identifications, every conclusion drawn from such material would be erroneous. Although ticks have attracted much interest in the past few years, this interest has not necessarily been accompanied by an adequate taxonomic expertise. The taxonomy of ticks is a rather complex topic, which is still the subject of debate. The identification of ticks is still mainly (if not only) based on the morphology of the specimens and on individual expertise, with the support of a variety of keys that describe the morphology of the stages and the differences between closely related species. Publications that cover every species in a particular area or country are seldom available, with a few notable exceptions (Filippova, 1977, 1997; Keirans and Clifford, 1978; Matthysse and Colbo, 1987; Durden and Keirans, 1996; Walker et al., 2000). A literature search on the epidemiology of tick-transmitted pathogens published in the past few decades suggested that few of the authors had taxonomic expertise, and there is usually no indication of how the ticks in their studies were identified. Contemporary researchers tend to use convenient, though not always relevant, reprints (available for example in their institute library or on the internet). This approach reveals a lack of criticism in a critical step of their research. It has become customary to identify only the adult stage of ticks, probably because it is easily collected from domestic hosts and easier to identify that the immatures. However, this provides an unreliable overview of the diversity of ticks present and their relative importance in the community of hosts and pathogens.

Adequate identification methods based on DNA or proteome analysis of ticks such as barcoding and mass spectrometry, are under development (Lv et al., 2013; Yssouf et al., 2013), but much work is still necessary to verify their significance. The complete genome has been sequenced for only I. scapularis (Pagel Van Zee et al., 2007), and the reliability of the sequences of other species deposited in GenBank is uncertain, as has proved to be the case for other taxa (Bridge et al., 2003; Wägele et al., 2011). Knowledge about the intra- and interspecific variation of the few molecular sequences so far examined is limited and therefore the significance of sequence variation is difficult to interpret. At present, identification of ticks based only on molecular data should be discouraged, and while a potential source for future research, sequences available in GenBank should not be considered as the "gold standard" for tick identification.

\section{IDENTIFICATION OF TICK HOSTS BY DETERMINING THE SOURCE OF TICK BLOOD-MEALS}

Another biotic component of these systems are the hosts. Several studies have addressed the importance of examining the complete community of hosts in a territory to estimate their relative contribution in supporting the various tick species present and the pathogens the ticks transmit (Levin and Fish, 1998; Ostfeld and Keesing, 2000; Logiudice et al., 2003; Tyre et al., 2003). In sylvatic habitats the accessibility of the hosts is an obvious problem and determination of their role in the maintenance of ticks and pathogens has traditionally required expensive and exhaustive trapping or shooting. However, several variations on a method to detect host DNA in the remnants of blood within questing ticks are now available. These consist of amplifying fragments of conserved genes such as cytochrome $b$ (Kirstein and Gray, 1996); 18SrRNA (Pichon et al., 2003) and 12SrRNA (Humair et al., 2007), followed by reverse line blot (RLB) or sequence analysis. Some success has been achieved in determining the role different host species play in maintaining populations of Ixodes ricinus and in identifying possible reservoir hosts of Borrelia burgdorferi sensu lato (Estrada-Peña et al., 2005; Pichon et al., 2005; Moran Cadenas et al., 2007), but the method has 
proved highly susceptible to contamination and sensitivity problems. While there is impetus for such an approach, at present it cannot be considered sufficiently robust for general deployment in field studies. Recently developed methods to identify the blood meal source in questing ticks using proteome profiling techniques (Wickramasekara et al., 2008; Onder et al., 2013) or natural isotope analysis (Schmidt et al., 2011) may be interesting alternatives.

\section{EVALUATION AND STANDARD DENOMINATIONS OF TICKS-HOSTS-PATHOGENS RELATIONSHIPS}

The interactions between the elements of any tick-host-pathogen system and interactions with other transmission cycles are key features to understand pathogen prevalence in questing ticks and in vertebrates. The evaluation of such interactions is a necessary preliminary (though complex) step in risk assessment. There are several reviews addressing the survival strategies of ticktransmitted pathogens, and how the ecology of ticks and their hosts may shape such prevalence (Mannelli et al., 2012), but these aspects are beyond the scope of this review. It is necessary to summarize a framework of relevant ecological terminology proposed by Kahl et al. (2002) that was largely based on terms introduced by Pavlovsky (1966), and continued by Balashov (1972), Ginsberg (1993); Nuttall and Labuda (1994); Sonenshine and Mather (1994), and Randolph and Craine (1995). Such a framework has been constructed to address major pitfalls in ecological research, identifying common errors and faulty interpretations occurring in the literature.

The eco-epidemiological status of ticks and their hosts cannot be determined by field studies alone. Complementary laboratory studies should be designed to capture the essentials of the role played by each element of the system. Some hypotheses can only be confirmed after tests have been conducted in the laboratory to remove the inherent variability of the field data. To designate a tick as a vector of a given pathogen, the three following criteria must be confirmed:

(1) Ability of ticks to become infected by feeding on the infected hosts. Whenever possible these studies should be carried out using uninfected ticks and natural, presumed reservoir hosts.

(2) The ability of fed ticks to trans-stadially pass the pathogen through the following molt to the next stage of the life cycle, or the F1 generation.

(3) The ability of molted stages to transmit the pathogen to naive hosts during blood feeding.

In summary, to qualify as a vector, the tick must (1) feed on infectious vertebrates (2) acquire the pathogen during the blood meal (3) maintain the pathogen through one or more trans-stadial molts and (4) transmit the pathogen to previously unexposed hosts while feeding again (Kahl et al., 2002). Assigning vector or reservoir status to a tick or a host species based solely on the detection of the DNA of the pathogen or evaluation of hosts by serology is not acceptable. Detection of pathogen DNA in a tick or host indicates that it possesses carrier status (see below for the definitions), and detection of antibodies in host sera merely indicates that an animal has been exposed to the pathogen. Whether or not transmission from tick to host or from host to tick is involved must be addressed experimentally in the laboratory.

Figure 2 outlines the steps in the chain of host-tick-pathogen relationships. Tick hosts (Figure $2 \mathrm{~A}$ ) include all vertebrates on

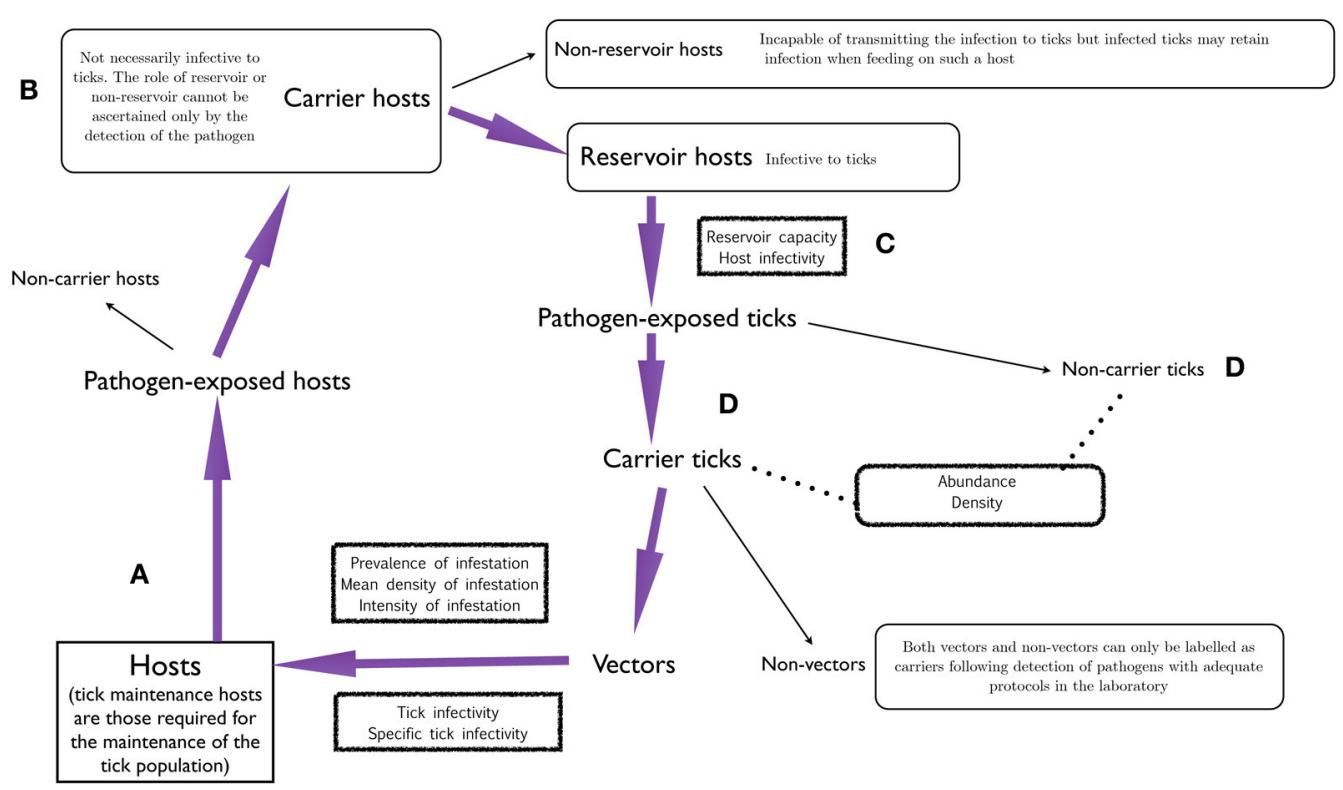

FIGURE 2|A chart describing the chain of events in the interface of ticks, hosts, and pathogens, aimed to delineate a set of standard denominations following a common framework (Kahl et al., 2002). Hosts (A) may be exposed to pathogens and then be carrier hosts (B). These may be reservoir hosts (C) that feed ticks exposed to pathogens. The ticks feeding on these reservoir hosts may be the carrier ticks (D) that are vectors of pathogens to new hosts. 
which ticks feed in nature. Local and regional tick abundance largely depends on the abundance of tick maintenance hosts (sometimes called amplifying hosts, a term also applied occasionally to vertebrates that transmit pathogens and in which the pathogens replicate). The lack of sufficient numbers of hosts or even the absence of a key host in a particular area may prevent the occurrence of a species of tick even if weather and other abiotic features are permissive. When hosts are fed on by infected vector ticks they may be pathogen-exposed and these hosts may be carriers or non-carriers. The latter cannot infect naive ticks. A carrier host (Figure 2B) is not necessarily infective to ticks and therefore the terms non-reservoir and reservoir must be used to define infectivity status. The former are incapable of transmitting the infection to uninfected ticks. There are two important terms that apply to reservoir hosts and are relevant as to how ticks feeding on them are exposed to pathogens (Figure 2C). Reservoir capacity describes the absolute contribution made by a particular reservoir host species to the natural prevalence of infection by a given pathogen within a certain site. Host infectivity denotes the efficiency with which the host transmits the infection to ticks feeding on it. Reservoir capacity is dependent upon its infectivity for feeding ticks and the duration of the infective period (Mather et al., 1989; Mannelli et al., 1993; Randolph and Craine, 1995; Kahl et al., 2002).

By feeding on reservoir hosts, ticks are exposed to pathogens and they may become non-carrier or carrier ticks (Figure 2D). Carrier ticks may be vectors or non-vectors, as already discussed. The terms tick infectivity and specific tick infectivity refer to the efficiency with which the infection is transmitted from ticks to hosts and the efficiency with which the infection is transmitted from a given tick species to a particular species of host, respectively, and these features must be addressed in the laboratory.

\section{MOLECULAR DIAGNOSTICS OF TICK-BORNE PATHOGENS}

For all eco-epidemiological studies on tick-borne diseases, correct identification of the tick-borne pathogen(s) in question is pivotal. Examples of conventional methods for the identification of pathogens include cell culture, immunofluorescence and microscopic techniques (Kahl et al., 2002), but the detection of pathogens was revolutionized following the advent of the polymerase chain reaction (PCR) in the mid-1980s. The PCR made it possible to amplify minute amounts of (pathogen) DNA from biological samples such as ticks or blood for subsequent analysis by means of gel electrophoresis, restriction fragment length polymorphism (RFLP), sequencing, or hybridization probing techniques such as the RLB (Persing et al., 1990; Rijpkema et al., 1995; Richards, 2012). Quantification of the copy number of pathogen DNA initially present in tick or host samples became reality following the development of real-time PCR, in which the amount of product formed during the PCR reaction can be monitored (Pusterla et al., 1999).

In general, a well-designed PCR assay has a superior sensitivity and specificity vs. direct-detection methods, such as visual inspection of blood or tick hemolymph smears. It also offers the advantage over serological methods in that it can document current infection in ticks and animals and not simply past exposure to a pathogen, and does not require adaptation to different animal species, which is particularly useful in the examination of samples collected from wildlife. Unfortunately, the widespread use of PCR has led to a tendency to incriminate tick species as vectors based solely on the detection of pathogen DNA. Although the screening of ticks for pathogen DNA by PCR may be useful to identify potential tick vectors or reservoir vectors and to determine the tick-borne pathogens which circulate in a defined area, the findings must always be interpreted with great caution, as positive results may be caused by remnants of imbibed blood meals containing pathogen DNA, which does not necessarily implicate the tick as a vector (Kahl et al., 2002). This is further illustrated by experimental studies in which pathogen DNA was detected by PCR in non-vector species that had fed on infected animals as larvae, but were not capable of transmitting the pathogen in vivo (Des Vignes et al., 1999; Soares et al., 2006). To circumvent this problem, an alternative approach is to detect pathogens or pathogen DNA in the salivary glands of ticks. It should, however, be noted that certain pathogens such as B. burgdorferi s.l. are restricted primarily to the midgut of infected ticks and migrate to the salivary glands only during feeding (De Silva and Fikrig, 1995); pathogen DNA of B. burgdorferi s.l. is therefore unlikely to be found in the salivary glands of unfed ticks. For the tickborne bacterium Anaplasma centrale, it has been demonstrated that colonization of the salivary glands does not prove that a tick can transmit the pathogen to a host; the salivary glands may act as a distinct barrier for the efficient pathogen transmission (Ueti et al., 2007). Hence it is necessary to perform transmission experiments to confirm the vector capacity of a given tick species.

Following collection and the correct identification of ticks, the first step in the laboratory is the extraction of nucleic acids. Collected ticks can be used directly for DNA extraction, stored in $70 \%$ ethanol or cryopreserved (Mtambo et al., 2006). Since PCR inhibitors can be present in engorged as well as in unfed ticks (Schwartz et al., 1997), DNA extraction methods which are proven to eliminate inhibitors from the purified DNA template should be used. Other methods to overcome PCR inhibition are reviewed elsewhere (Rådström et al., 2004). Ticks should be clean and free of debris such as plugs of cement prior to homogenization or dissection. Live or freshly killed ticks can be dissected to isolate tissues such as salivary glands for subsequent DNA extraction. Pictorial guides on commonly used methods to collect tick tissues, saliva or hemolymph were published recently (Edwards et al., 2009; Patton et al., 2012). When DNA is extracted from tick tissues, adequate cleaning of materials between processing individual samples and washing of tissues is required to rule out carry-over contamination between different ticks and tissues.

When designing PCR experiments, it is important to prevent the unspecific amplification of DNA. Since the nucleotide sequences of primers presented in scientific papers are not always accurate or may be outdated when novel nucleotide sequence information for related species has become available (Baker et al., 2003), it is advisable to check the specificity of the primers which are to be used. This can for instance be done using BLAST (http:// blast.ncbi.nlm.nih.gov/). Similarly, the design of oligonucleotide 
probes used for hybridization assays such as the RLB also requires critical appraisal and validation, to ensure their specificity and prevent cross-reactions that may lead to false-positive results (Nagore et al., 2004; Bhoora et al., 2009).

The high sensitivity of PCR and other PCR-based technologies such as loop-mediated isothermal amplification (LAMP) renders it prone to false-positive results due to exogenous contamination. Guidelines to avoid contamination by following the principles of GLP have been published and also include a strict spatial separation of pre-PCR and post-PCR activities, a unidirectional workflow, decontamination measures, and sufficient and adequate negative controls (Lo and Chan, 2006). An additional measure that can be taken to prevent carry-over contamination of PCR amplicons formed during previous PCRs is the use of dUTPs with Uracil DNA Glycosylase (UDG) which renders uracil-containing DNA from previous PCR reactions incapable of being copied by Taq DNA polymerases (Longo et al., 1990). The dUTP/UDG protocol is not compatible with proof-reading DNA polymerases. Read-out of results from certain LAMP tests can be done without opening the reaction tubes, which also reduces the chances of amplicon contamination (Francois et al., 2011).

Whatever method is used for post-PCR analysis, it remains important to use common sense when analyzing the data. Unconventional results in particular have to be verified, and visual inspection of blood smears is often essential, even in the post-genomic era.

\section{MATHEMATICAL MODELS APPLIED TO CAPTURE THE NICHES OF TICKS FROM SURVEYS}

Climate change and climatic variations within seasons are likely to influence the epidemiology of vector-borne diseases (Patz et al., 2003). There are reports on field observations of the spread of ticks in several areas of the world (Tälleklint and Jaenson, 1998; Daniel et al., 2003; Materna et al., 2005; Ogden et al., 2008; Jaenson and Lindgren, 2011; Madder et al., 2012). This has kindled interest in capturing the basic patterns of climate and other environmental features regulating the geographical ranges of ticks and their associated pathogens. Since this is a growing discipline in the field, we only outline some misconceptions that may affect the performance and conclusions drawn from modeling exercises.

The capture of data to estimate the direct and indirect effects of weather on the distribution, phenology or spread of ticks is commonly based on the idea of "climate" or "environmental" niche (Soberón and Nakamura, 2009). This is defined as the "intersection" of values of the climatic variables at which optimal development and mortality occur, resulting in the best performance of the population. This concept assumes that the most important factors driving the performance of ticks are related to weather and that niches can be reconstructed by relating data on the occurrence of the tick with datasets summarizing climate, topographic, edaphic, and other "abiotic" or "ecological" variables. It is also assumed that (1) there is a niche conservatism and the organism tracks the sites where adequate conditions exist (not taking into account adaptations of local populations to local weather) and (2) the complete distribution range of the organism has been surveyed. The tick's niche is evaluated to infer its associations with environmental variables. Inference is later projected into a target area to obtain a map that explains "how similar" the conditions in space are, compared with the ones where the tick has been collected. Such a measure of similarity is not an estimate of abundance or of distribution, although it is incorrectly assumed to be a "risk map," in which "climate similarity" is interpreted as a direct estimator of abundance. Many other variables, including the fine scale distribution of hosts, human factors altering the habitat, geographical barriers to host movements and the uncertain effects of the vegetation, influence the abundance of ticks (Estrada-Peña et al., 2012) and therefore the crude map is not a direct projection of the spatial risk.

Other procedural gaps in the evaluation of the environmental niche of a tick involve the inadequate utilization of interpolated climate datasets, which inflate the models because of autocorrelation (Legendre, 1993) and colinearity (Storch et al., 2003). Both factors strongly modify the apparent influence of variables that affect the distribution of an organism, resulting in the false perception of a well-fitted model. Determination of climate niche is also affected by the partial and subjective use of a limited number of collections of the tick to be modeled (see Porretta et al., 2013), by the inclusion of variables that are correlated with others to build the model, such as altitude and temperature (i.e., DiukWasser et al., 2006), or by the selection of variables based on the predictive performance of the best model, but lacking a biological significance [as mentioned by Braunisch et al. (2013)]. The utilization of physical altitude or elevation in attempts to relate tick occurrence patterns to environmental variables is misconceived. It is obvious that, at a local scale, elevation greatly affects the patterns of climate, decreasing the temperature over the altitudinal gradients and influencing the rainfall. In every case the performance of the model will be inflated giving the false perception of a robust model, biasing the conclusions and the projections. Because of the structure of the algorithms explaining the distribution of an organism (Elith et al., 2010), the use of covariates such as rainfall will produce a false estimate of a good fit, apparently covering the known distribution of the tick. It will, however, be a fortuitous correlation, and the response of the distribution of the tick will not parallel changes in rainfall.

\section{CONCLUSIONS}

Increasing interest in tick-borne zoonotic agents, accompanied by the development of accurate and accessible molecular tools, has resulted in a marked upsurge of published papers on the topic over the past three decades. Although this has resulted in distinct progress in knowledge, some of the hard-learned lessons of the past have inevitably been overlooked during this period of intense activity. Typical problems include errors in tick identification (especially of immature instars), premature or erroneous reporting of ticks as new vectors and hosts as reservoirs, superficial data on the abundance and seasonal activity of ticks, inappropriate use of statistical methodology, and uncontrolled laboratory diagnostic procedures. The very ready accessibility of research publications online, at least in abstract form, tends to exacerbate the situation in that, as a result of superficial reading and subsequent citing, an erroneous conclusion can quickly become 
embedded in the literature. In this review we have described what consensus opinion views as the correct methodologies for obtaining and interpreting data in research on ticks and ticktransmitted pathogens and have highlighted and illustrated some

\section{REFERENCES}

Anderson, D. B. (1936). Relative humidity or vapor pressure deficit. Ecology 17, 277-282. doi: 10.2307/1931468

Baker, G. C., Smith, J. J., and Cowan, D. A. (2003). Review and re-analysis of domain-specific $16 \mathrm{~S}$ primers. J. Microbiol. Methods 55, 541-555. doi: 10.1016/j.mimet.2003.08.009

Balashov, Y. S. (1972). "Bloodsucking ticks (Ixodoidea) - vectors of diseases of man and animals," in Miscellaneous Publications of the Entomological Society of America. [Cairo: Medical Zoology Department, U.S. Naval Medical Research Unit Number Three (NAMRU-3)], 161-376.

Belozerov, V. N. (1982). "Diapause and biological rhythms in ticks," in Physiology of Ticks, eds F. D. Obenchain and R. Galun (Oxford: Pergamon Press), 469-500.

Belozerov, V. N., and Kvitko, N. V. (1965). Main features of photoperiodic reaction in Dermacentor marginatus Sulz. Ticks (Ixodoidea). Zool. Zh. 44, 363-372.

Bhoora, R., Franssen, L., Oosthuizen, M. C., Guthrie, A. J., Zweygarth, E., Penzhorn, B. L., et al. (2009). Sequence heterogeneity in the $18 \mathrm{~S}$ rRNA gene within Theileria equi and Babesia caballi from horses in South Africa. Vet. Parasitol. 159, 112-120. doi: 10.1016/j.vetpar.2008.10.004

Braunisch, V., Coppes, J., Arlettaz, R., Suchant, R., Schmid, H., and Bollmann, K. (2013). Selecting from correlated climate variables: a major source of uncertainty for predicting distributions under climate change. Ecography 36, 001-013. doi: 10.1111/j.1600-0587.2013.00138.x

Bridge, P. D., Roberts, P. J., Spooner, B. M., and Panchal, G. (2003). On the unreliability of published DNA sequences. New Phytol. 160, 43-48. doi: 10.1046/j.1469-8137.2003.00861.x

Brownstein, J. S., Holford, T. R., and Fish, D. (2003). A climate-based model predicts the spatial distribution of the Lyme disease vector Ixodes scapularis in the United States. Environ. Health Perspect. 111, 1152-1157. doi: 10.1289/ehp.6052

Daniel, M., Danielova, V., Kriz, B., Jirsa, A., and Nozicka, J. (2003). Shift of the tick Ixodes ricinus and tick-borne encephalitis to higher altitudes in central Europe. Eur J. Clin. Microbiol. Infect. Dis. 22, 327-328. L., and Fish, D. (1996). Timing of Ixodes scapularis (Acari: Ixodidae) oviposition and larval activity in southern New York. J. Med. Entomol. 33, 140-147.

De Silva, A. M., and Fikrig, E. (1995). Growth and migration of Borrelia burgdorferi in Ixodes ticks during blood feeding. Am. J. Trop. Med. Hyg. 53, 397-404.

Des Vignes, F., Levin, M. L., and Fish, D. (1999). Comparative vector competence of Dermacentor variabilis and Ixodes scapularis (Acari: Ixodidae) for the agent of human granulocytic ehrlichiosis. J. Med. Entomol. 36, 182-185.

Diuk-Wasser, M. A., Gatewood, A. G., Cortinas, M. R., YaremychHamer, S., Tsao, J., Kitron, U., et al. (2006). Spatiotemporal patterns of host-seeking Ixodes scapularis nymphs (Acari: Ixodidae) in the 166-176. doi: 10.1603/0022-2585 (2006)043[0166:SPOHIS]2.0.CO;2

Durden, L. A., and Keirans, J. E. (1996). Nymphs of the Genus Ixodes (Acari: Ixodidae) of the United States: Taxonomy, Identification Key, Distribution, Hosts, and Medical/Veterinary Importance. Lanham, MD: Entomological Society of America.

Edwards, K. T., Goddard, J., and VarelaStokes, A. S. (2009). Examination of the internal morphology of the ixodid tick, Amblyomma maculatum Koch, (Acari: Ixodidae); a "how-to" pictorial dissection guide. Midsouth Entomol. 2, 28-39.

Eisen, L. (2008). Climate change and tick-borne diseases: a research field in need of long-term empirical field studies. Int. J. Med. Microbiol. 298, 12-18. doi: 10.1016/j.ijmm.2007.10.004

Elith, J., Kearney, M., and Phillips, S. (2010). The art of modelling rangeshifting species. Methods Ecol. Evol. 1, 330-342. doi: 10.1111/j.2041210X.2010.00036.X

Estrada-Peña, A., Farkas, R., Jaenson, T. G. T., Koenen, F., Madder, M., Pascucci, I., et al. (2013). Association of environmental traits with the geographic ranges of ticks (Acari: Ixodidae) of medical and veterinary importance in the
Daniels, T. J., Falco, R. C., Curran, K. United States. J. Med. Entomol. 43,

of the common procedural missteps, with suggested solutions where possible. It is hoped that this review will contribute to a more considered and thoughtful approach to this complex topic in the future.

western Palearctic. A digital data set. Exp. Appl. Acarol. 59, 351-366.

Estrada-Peña, A., Martinez, J. M., Acedo, C. S., Quilez, J., and Del Cacho, E. (2004). Phenology of the tick, Ixodes ricinus, in its southern distribution range (central Spain). Med. Vet. Entomol. 18, 387-397.

Estrada-Peña, A., Osacar, J. J., Pichon, B., and Gray, J. S. (2005). Hosts and pathogen detection for immature stages of Ixodes ricinus (Acari: Ixodidae) in North-Central Spain. Exp. Appl. Acarol. 37, 257-268.

Estrada-Peña, A., Sanchez, N., and Estrada-Sanchez, A. (2012). An assessment of the distribution and spread of the tick Hyalomma marginatum in the western Palearctic under different climate scenarios. Vector Borne Zoonotic Dis. 12, 758-768.

Filippova, N. A. (1977). Ixodid Ticks of the Subfamily Ixodinae. San Petersburgo: Fauna SSSR, Paukoobraznye.

Filippova, N. A. (1997). Ixodid Ticks of the Subfamily Amblyomminae. St. Petersburg: Nauka Publishing House.

Francois, P., Tangomo, M., Hibbs, J., Bonetti, E. J., Boehme, C. C., Notomi, T., et al. (2011). Robustness of a loop-mediated isothermal amplification reaction for diagnostic applications. FEMS Immunol. Med. Microbiol. 62, 41-48. doi: 10.1111/j.1574-695X.2011.00785.x

Franke, J., Hildebrandt, A., and Dorn, W. (2013). Exploring gaps in our knowledge on Lyme borreliosis spirochaetes - updates on complex heterogeneity, ecology, and pathogenicity. Ticks Tick Borne Dis. 4, 11-25. doi: 10.1016/j.ttbdis.2012.06.007

Gale, P., Estrada-Peña, A., Martinez, M., Ulrich, R. G., Wilson, A., Capelli, G., et al. (2010). The feasibility of developing a risk assessment for the impact of climate change on the emergence of Crimean-Congo haemorrhagic fever in livestock in Europe: a Review. J. Appl. Microbiol. 108, 1859-1870.

Gardiner, W. P., and Gray, J. S. (1986). A computer-simulation of the effects of specific environmental factors on the development of the sheep tick Ixodes ricinus L. Vet. Parasitol. 19, 133-144. doi: 10.1016/03044017(86)90041-5
Gilot, B., Degeilh, B., Pichot, J., Doche, B., Guiguen, C., Boero, L., et al. (1996). Prevalence of Borrelia burgdorferi (sensu lato) in Ixodes ricinus (L) populations in France, according to a phytoecological zoning of the territory. Eur. J. Epidemiol. 12, 395-401. doi: 10.1007/BF00145304

Gilot, B., Laforge, M. L., Cabassu, J. P., and Romani, M. (1992). Elements for an ecological cartography of the populations of Rhipicephalus sanguineus group (Acarina, Ixodoidea) in the agglomeration of Marseilles, in relation with the different forms of town-planning. Acarologia 33, 17-33.

Ginsberg, H. S. (ed.). (1993). Ecology and Environmental Management of Lyme Disease. New Brunswick, NJ: Rutgers University Press, 224.

Gray, J. S. (1982). The development and questing activity of Ixodes ricinus (L) (Acari, Ixodidae) under field conditions in Ireland. Bull. Entomol. Res. 72, 263-270. doi: 10.1017/S0007485300010567

Gray, J.S. (1991). The development and seasonal activity of the tick Ixodes ricinus: a vector of Lyme borreliosis. Rev. Med. Vet. Entomol. 79, 323-333.

Gray, J. S. (2008). Ixodes ricinus seasonal activity: implications of global warming indicated by revisiting tick and weather data. Int. J. Med. Microbiol. 298, 19-24. doi: 10.1016/j.ijmm.2007.09.005

Gray, J. S., Kahl, O., Janetzki, C., and Stein, J. (1992). Studies on the ecology of Lyme disease in a deer forest in county Galway, Ireland. J. Med. Entomol. 29, 915-920.

Humair, P. F., Douet, V., Cadenas, F. M., Schouls, L. M., Van De Pol, I., and Gern, L. (2007). Molecular identification of bloodmeal source in Ixodes ricinus ticks using $12 \mathrm{~S}$ rDNA as a genetic marker. J. Med. Entomol. 44, 869-880. doi: 10.1603/ 0022-2585(2007)44[869:MIOBSI]2. $0 . \mathrm{CO} ; 2$

Huston, M. A. (1999). Local processes and regional patterns: appropriate scales for understanding variation in the diversity of plants and animals. Oikos 86, 393-401. doi: $10.2307 / 3546645$

Jaenson, T. G., Eisen, L., Comstedt, P., Mejlon, H. A., Lindgren, E., Bergström, S., et al. (2009). Risk indicators for the tick Ixodes ricinus and Borrelia burgdorferi sensu 
lato in Sweden. Med. Vet. Entomol. 23, 226-237. doi: 10.1111/j.13652915.2009.00813.x

Jaenson, T. G. T., and Lindgren, E. (2011). The range of Ixodes rici$n u s$ and the risk of contracting Lyme borreliosis will increase northwards when the vegetation period becomes longer. Ticks Tick Borne Dis. 2, 44-49. doi: 10.1016/j.ttbdis.2010.10.006

Kahl, O., and Alidousti, I. (1997). Bodies of liquid water as a source of water gain for Ixodes ricinus ticks (Acari: Ixodidae). Exp. Appl. Acarol. 21, 731-746. doi: 10.1023/A:1018469021161

Kahl, O., Gern, L., Eisen, L., and Lane, R. S. (2002). "Ecological research on Borrelia burgdorferi sensu lato: terminology and some methodological pitfalls," in Lyme Borreliosis: Biology, Epidemiology and Control, eds J. S. Gray, O. Kahl, R. S. Lane, and G. Stanek (New York, NY: CABI Publishing), 29-46.

Kahl, O., and Knülle, W. (1988). Watervapor uptake from subsaturated atmospheres by engorged immature ixodid ticks. Exp. Appl. Acarol. 4, 73-83. doi: 10.1007/BF01213843

Keirans, J. E., and Clifford, C. M. (1978). The genus Ixodes in the United States: a scanning electron microscope study and key to the adults. J. Med. Entomol. S2, 1-149.

Kirstein, F., and Gray, J. S. (1996). A molecular marker for the identification of the zoonotic reservoirs of lyme borreliosis by analysis of the blood meal in its European vector Ixodes ricinus. Appl. Environ. Microbiol. 62, 4060-4065.

Knülle, W., and Wharton, G. W. (1964). Equilibrium humidities in arthropods and their ecological significance. Acarologia 6, 299-306.

Labuda, M., Nuttall, P. A., Kožuch, O., Elečkovà, E., Williams, T., Žuffová, E., et al. (1993). Nonviraemic transmission of tick-borne encephalitis virus: a mechanism for arbovirus survival in nature. Experientia 49, 802-805. doi: 10.1007/BF01923553

Lane, R. S., Anderson, J. R., Yaninek, J. S., Burgdorfer, W. (1985). Diurnal host seeking of adult Pacific Coast ticks, Dermacentor occidentalis (Acari: Ixodidae), in relation to vegetational type, meteorological factors, and rickettsial infection rates in California, USA. J. Med. Entomol. 22, 558-571.

Lane, R. S., Kleinjan, J. E., Schoeler, G. B. (1995). Diel activity of nymphal Dermacentor occidentalis and Ixodes pacificus (Acari: Ixodidae) in relation to meteorological factors and host activity periods. J. Med. Entomol. 32, 290-299.

Lane, R. S., Peavey, C. A., Padgett, K. A., Hendson, M. (1999). Life history of Ixodes (Ixodes) jellisoni (Acari: Ixodidae) and its vector competence for Borrelia burgdorferi sensu lato. J. Med. Entomol. 36, 329-340.

Lees, A. D. (1946). The water balance in Ixodes ricinus $\mathrm{L}$ and certain other species of ticks. Parasitology 37, 1-20. doi: 10.1017/S0031182000013093

Lees, A. D., and Milne, A. (1951). The seasonal and diurnal activities of individual sheep ticks (Ixodes ricinus L). Parasitology 41, 189-208. doi: $10.1017 / S 0031182000084031$

Legendre, P. (1993). Spatial autocorrelation - trouble or new paradigm. Ecology 74, 1659-1673. doi: 10.2307/1939924

Levin, M. L., and Fish, D. (1998). Density-dependent factors regulating feeding success of Ixodes scapularis larvae (Acari: Ixodidae). J. Parasitol. 84, 36-43. doi: $10.2307 / 3284526$

Lindsay, L. R., Mathison, S. W., Barker, I. K., McEwen, S. A., Gillespie, T. J., and Surgeoner, G. A. (1999). Microclimate and habitat in relation to Ixodes scapularis (Acari: Ixodidae) populations on Long Point, Ontario, Canada. J. Med. Entomol. 36, 255-262.

Lo, Y. M., and Chan, K. C. (2006). Setting up a polymerase chain reaction laboratory. Methods Mol. Biol. 336, 11-18.

Logiudice, K., Ostfeld, R. S., Schmidt, K. A., and Keesing, F. (2003). The ecology of infectious disease: effects of host diversity and community composition on Lyme disease risk. Proc. Natl. Acad. Sci. U.S.A. 100, 567-571. doi: $10.1073 /$ pnas. 0233733100

Longo, M. C., Berninger, M. S., and Hartley, J. L. (1990). Use of uracil DNA glycosylase to control carry-over contamination in polymerase chain reactions. Gene 93, 125-128. doi: 10.1016/0378-1119 (90)90145-H

Lv, J., Wu, S., Zhang, Y., Zhang, T., Feng, C., Jia, G., et al. (2013). Development of a DNA barcoding system for the Ixodida (Acari: Ixodida). Mitochondrial DNA doi: 10.3109/19401736.2013.792052. [Epub ahead of print].

Madder, M., Adehan, S., De Deken, R., Adehan, R., and Lokossou, R. (2012). New foci of Rhipicephalus microplus in West Africa. Exp. Appl. Acarol. 56, 385-390. doi: 10.1007/s10493-012-9522-4
Madder, M., and Berkvens, D. L. (1997). Evaluation of an in vitro method to measure behavioural diapause in the tick Rhipicephalus appendiculatus (Acarina: Ixodidae) in the laboratory. Parasitology 115(Pt 1), 97-100. doi: 10.1017/S0031182097001030

Mannelli, A., Bertolotti, L., Gern, L., and Gray, J. (2012). Ecology of Borrelia burgdorferi sensu lato in Europe: transmission dynamics in multi-host systems, influence of molecular processes and effects of climate change. FEMS Microbiol. Rev. 36, 837-861. doi 10.1111/j.1574-6976.2011.00312.x

Mannelli, A., Boggiatto, G., Grego, E., Cinco, M., Murgia, R., Stefanelli, S., et al. (2003). Acarological risk of exposure to agents of tick-borne zoonoses in the first recognized Italian focus of Lyme borreliosis. Epidemiol. Infect. 131, 1139-1147. doi: 10.1017/S0950268803001328

Mannelli, A., Kitron, U., Jones, C. J., and Slajchert, T. L. (1993). Ixodes dammini (Acari: Ixodidae) infestation on medium-sized mammals and blue jays in northwestern Illinois. J. Med. Entomol. 30 950-952.

Materna, J., Daniel, M., and Danielova, V. (2005). Altitudinal distribution limit of the tick Ixodes ricinus shifted considerably towards higher altitudes in central Europe: results of three years monitoring in the Krkonose Mts. (Czech Republic). Cent. Eur. J. Public Health 13, 24-28. Mather, T. N., Wilson, M. L., Moore, S. I., Riberio, J. M. C., and Spielman, A. (1989). Comparing the relatuve potential of rodents as reservoirs of the Lyme disease spirochete (Borrelia burgdorferi). Am. J. Epidemiol. 130, 143-150.

Matthysse, J. G., and Colbo, M. H. (1987). The Ixodid Ticks of Uganda. Together with Species Pertinent to Uganda Because of Their Present Known Distribution. College Park, MD: Entomological Society of America.

Medlock, J. M., Hansford, K. M., Bormane, A., Derdakova, M., Estrada-Peña, A., George, J. C., et al. (2013). Driving forces for changes in geographical distribution of Ixodes ricinus ticks in Europe. Parasit. Vectors 6:1. doi 10.1186/1756-3305-6-1

Menzel, A., Sparks, T. H., Estrella, N., Koch, E., Aasa, A., Ahas, R. et al. (2006). European phenological response to climate change matches the warming pattern. Glob. Chang. Biol. 12, 1969-1976. doi: 10.1111/j.1365-2486.2006.01193.x
Moran Cadenas, F., Rais, O., Humair, P. F., Douet, V., Moret, J., and Gern, L. (2007). Identification of host bloodmeal source and Borrelia burgdorferi sensu lato in field-collected Ixodes ricinus ticks in Chaumont (Switzerland). J. Med. Entomol. 44, 1109-1117. doi: $\quad 10.1603 / 0022-2585(2007) 44$ [1109:IOHBSA]2.0.CO;2

Mtambo, J., Van Bortel, W., Madder, M., Roelants, P., and Backeljau, T. (2006). Comparison of preservation methods of Rhipicephalus appendiculatus (Acari: Ixodidae) for reliable DNA amplification by PCR. Exp. Appl. Acarol. 38, 189-199. doi: 10.1007/s10493-006-0004-4

Nagore, D., Garcia-Sanmartin, J., Garcia-Perez, A. L., Juste, R. A., and Hurtado, A. (2004). Identification, genetic diversity and prevalence of Theileria and Babesia species in a sheep population from Northern Spain. Int. J. Parasitol. 34, 1059-1067. doi: 10.1016/j.ijpara.2004.05.008

Norval, R. A. I., Lawrence, J. A., Young, A. S., Perry, B. D., Dolan, T. T., and Scott, J. (1991). Theileria parva influence of vector, parasite and host relationships on the epidemiology of theileriosis in southern Africa. Parasitology 102, 347-356. doi: $10.1017 / S 0031182000064295$

Nuttall, P. A., and Labuda, M. (1994). "Tick-borne encephalitis subgroup," in Ecological Dynamics of Tick-Borne Zoonoses, eds D. E. Sonenshine and T. N. Mather (New York, NY: Oxford University Press), 351-391.

Ogden, N. H., St-Onge, L., Barker, I. K., Brazeau, S., Bigras-Poulin, M., Charron, D. F., et al. (2008). Risk maps for range expansion of the Lyme disease vector, Ixodes scapularis, in Canada now and with climate change. Int. J. Health Geogr 7:24. doi: 10.1186/1476-072X-7-24

Onder, O., Shao, W., Kemps, B. D., Lam, H., and Brisson, D. (2013). Identifying sources of tick blood meals using unidentified tandem mass spectral libraries. Nat. Commun. 4, 1746. doi: 10.1038/ncomms 2730

Ostfeld, R. S., Glass, G. E., and Keesing, F. (2005). Spatial epidemiology: an emerging (or re-emerging) discipline. Trends Ecol. Evol. 20, 328-336. doi: 10.1016/j.tree.2005.03.009

Ostfeld, R. S., and Keesing, F. (2000). Biodiversity and disease risk: the case of lyme disease. Conserv. Biol. 14, 722-728. doi: 10.1046/j.15231739.2000.99014.x

Padgett, K. A., and Lane, R. S. (2001). Life cycle of Ixodes pacificus (Acari 
Ixodidae): timing of developmental processes under field and laboratory conditions. J. Med. Entomol. 38, 684-693. doi: 10.1603/0022-258538.5.684

Pagel Van Zee, J., Geraci, N. S., Guerrero, F. D., Wikel, S. K., Stuart, J. J., Nene, V. M., et al. (2007). Tick genomics: the Ixodes genome project and beyond. Int. J. Parasitol. 37, 1297-1305. doi: 10.1016/j.ijpara.2007.05.011

Patton, T. G., Dietrich, G., Brandt, K., Dolan, M. C., Piesman, J., and Gilmore, R. D. Jr. (2012). Saliva, salivary gland, and hemolymph collection from Ixodes scapularis ticks. J. Vis. Exp. pii:3894. doi: 10.3791/ 3894

Patz, J. A., Githeko, A. K., McCarthy, J. P., Hussein, S., Confalonieri, U., and De Wet, N. (2003). "Climate change and infectious diseases," in Climate Change and Human Health - Risks and Responses, eds A. J. McMichael, D. H. Campbell-Lendrum, C. F. Corvalan, K. L. Ebi, A. K. Githeko, J. D. Scheraga, and A. Woodward (Geneva: WHO), 103-137.

Pavlovsky, E. N. (1966). "Natural nidality of transmisible diseases with special reference to the landscape epidemiology of zooanthroponosis," ed N. D. Levine (Urbana, IL: University of Illinois Press), 261.

Pegram, R. G., and Banda, D. S. (1990). Ecology and phenology of cattle ticks in Zambia: development and survival of free-living stages. Exp. Appl. Acarol. 8, 291-301. doi: 10.1007/BF01202139

Pegram, R. G., Mwase, E. T., Zivkovic, D., and Jongejan, F. (1988). Morphogenetic diapause in Amblyomma variegatum (Acari: Ixodidae). Med. Vet. Entomol. 2, 301-307. doi: 10.1111/j.13652915.1988.tb00200.x

Perret, J. L., Guerin, P. M., Diehl, P. A., Vlimant, M., and Gern, L. (2003). Darkness induces mobility, and saturation deficit limits questing duration, in the tick Ixodes ricinus. J. Exp. Biol. 206, 1809-1815. doi: 10.1242/jeb.00345

Perret, J. L., Guigoz, E., Rais, O., and Gern, L. (2000). Influence of saturation deficit and temperature on Ixodes ricinus tick questing activity in a Lyme borreliosisendemic area (Switzerland). Parasitol. Res. 86, 554-557. doi: $10.1007 / \mathrm{s} 004360000209$

Perret, J. L., Rais, O., and Gern, L. (2004). Influence of climate on the proportion of Ixodes ricinus nymphs and adults questing in a tick population. J. Med. Entomol. 41, 361-365. doi: 10.1603/0022-2585-41.3.361
Persing, D. H., Telford, S. R. 3rd., Spielman, A., and Barthold, S. W. (1990). Detection of Borrelia burgdorferi infection in Ixodes dammini ticks with the polymerase chain reaction. J. Clin. Microbiol. 28, 566-572.

Petney, T. N., Horak, I. G., and Rechav, Y. (1987). The ecology of the African vectors of heartwater, with particular reference to Amblyomma hebraeum and Amblyomma variegatum. Onderstepoort J. Vet. Res. 54, 381-395.

Pichon, B., Egan, D., Rogers, M., and Gray, J. (2003). Detection and identification of pathogens and host DNA in unfed host-seeking Ixodes ricinus L. (Acari: Ixodidae). J. Med. Entomol. 40, 723-731. doi: 10.1603/0022-2585-40.5.723

Pichon, B., Rogers, M., Egan, D., and Gray, J. (2005). Blood-meal analysis for the identification of reservoir hosts of tick-borne pathogens in Ireland. Vector Borne Zoonotic Dis. 5, 172-180. doi: 10.1089/vbz.2005.5.172

Porretta, D., Mastrantonio, V., Mona, S., Epis, S., Montagna, M., Sassera, D., et al. (2013). The integration of multiple independent data reveals an unusual response to Pleistocene climatic changes in the hard tick Ixodes ricinus. Mol. Ecol. $22,1666-1682$.

Pusterla, N., Huder, J. B., Leutenegger, C. M., Braun, U., Madigan, J. E., and Lutz, H. (1999). Quantitative real-time PCR for detection of members of the Ehrlichia phagocytophila genogroup in host animals and Ixodes ricinus ticks. J. Clin. Microbiol. 37, 1329-1331.

Rådström, P., Knutsson, R., Wolffs, P., Lövenklev, M., and Löfström, C. (2004). Pre-PCR processing: strategies to generate PCR-compatible samples. Mol. Biotechnol. 26, 133-146. doi: 10.1385/MB:26:2:133

Randolph, S. (2002). Quantitative ecology of ticks as a basis for transmission models of tickborne pathogens. Vector Borne Zoonotic Dis. 2, 209-215. doi: 10.1089/153036602321653789

Randolph, S. E. (1993). Climate, satellite imagery and the seasonal abundance of the tick Rhipicephalus appendiculatus in southern Africa: a new perspective. Med. Vet. Entomol. 7, 243-258. doi: 10.1111/j.13652915.1993.tb00684.x

Randolph, S. E. (1997). Abiotic and biotic determinants of the seasonal dynamics of the tick Rhipicephalus appendiculatus in South Africa. Med. Vet. Entomol.
11, 25-37. doi: 10.1111/j.13652915.1997.tb00286.x

Randolph, S. E. (2000). Ticks and tick-borne disease systems in space and from space. Adv. Parasitol. 47, 217-243. doi: 10.1016/S0065$308 \mathrm{X}(00) 47010-7$

Randolph, S. E. (2009). Tick-borne disease systems emerge from the shadows: the beauty lies in molecular detail, the message in epidemiology. Parasitology 136, 1403-1413. doi: 10.1017/S00311820 09005782

Randolph, S. E., and Craine, N. G. (1995). General framework for comparative quantitative studies on transmission of tick-borne diseases using Lyme borreliosis in Europe as an example. J. Med. Entomol. 32, 765-777.

Randolph, S. E., Green, R. M., Hoodless, A. N., and Peacey, M. F. (2002). An empirical quantitative framework for the seasonal population dynamics of the tick Ixodes ricinus. Int. J. Parasitol. 32, 979-989. doi: 10.1016/S0020-7519(02)00030-9

Randolph, S. E., and Storey, K. (1999). Impact of microclimate on immature tick-rodent host interactions (Acari: Ixodidae): implications for parasite transmission. J. Med. Entomol. 36, 741-748.

Rao, V. B., Cavalcanti, I. F. A., and Hada, K. (1996). Annual variation of rainfall over Brazil and water vapor characteristics over South America. J. Geophys. Res. Atmos. 101, 26539-26551. doi: 10.1029/96JD01936

Richards, A. L. (2012). Worldwide detection and identification of new and old rickettsiae and rickettsial diseases. FEMS Immunol. Med. Microbiol. 64, 107-110. doi: 10.1111/j.1574-695X.2011.00875.x

Rijpkema, S. G., Molkenboer, M. J., Schouls, L. M., Jongejan, F., and Schellekens, J. F. (1995). Simultaneous detection and genotyping of three genomic groups of Borrelia burgdorferi sensu lato in Dutch Ixodes ricinus ticks by characterization of the amplified intergenic spacer region between 5S and 23S rRNA genes. J. Clin. Microbiol. 33, 3091-3095.

Rudolph, D., and Knülle, W. (1974). Site and mechanism of water vapour uptake from the atmosphere in ixodid ticks. Nature 249, 84-85. doi $10.1038 / 249084 \mathrm{a} 0$

Salman, M., and Estrada-Peña, A. (2013). Emerging (re-emerging) Tick-Borne Infections and The Dissemination of Ticks. London: $\mathrm{CAB}$ International.
Schmidt, O., Dautel, H., Newton, J., and Gray, J. S. (2011). Natural isotope signatures of host blood are replicated in moulted ticks. Ticks Tick Borne Dis. 2, 225-227. doi: 10.1016/j.ttbdis.2011.09.006

Schulze, T. L., Jordan, R. A., and Hung, R. W. (2001). Effects of selected meterological factors on diurnal questing of Ixodes scapularis and Amblyomma americanum (Acari: Ixodidade). J. Med. Entomol. 38, 318-324. doi: 10.1603/00222585-38.2.318

Schwartz, I., Varde, S., Nadelman, R. B., Wormser, G. P., and Fish, D. (1997). Inhibition of efficient polymerase chain reaction amplification of Borrelia burgdorferi DNA in blood-fed ticks. Am. J. Trop. Med. Hyg. 56, 339-342.

Soares, C. A., Zeidner, N. S., Beard, C. B., Dolan, M. C., Dietrich, G., and Piesman, J. (2006). Kinetics of Borrelia burgdorferi infection in larvae of refractory and competent tick vectors. J. Med. Entomol. 43, 61-67. doi: 10.1603/0022-2585 (2006)043[0061:KOBBII]2.0.CO;2

Soberón, J., and Nakamura, M. (2009). Niches and distribution areas: concepts, methods and assumptions. Proc. Nat. Acad. Sci. U.S.A. 17, 19644-19650. doi: 10.1073/pnas.0901637106

Sonenshine, D. E., and Mather, T. N. (1994). Ecological Dynamics of Tick-Borne Zoonoses. New York, NY: Oxford University press.

Storch, D., Konvicka, M., Benes, J., Martinková, J., and Gaston, K. J. (2003). Distribution patterns in butterflies and birds of the Czech Republic: separating effects of habitat and geographical position. J. Biogeogr. 30, 1195-1205.

Tälleklint, L., and Jaenson, T. G. T. (1998). Increasing geographical distribution and density of Ixodes ricinus (Acari: Ixodidae) in central and northern Sweden. J. Med. Entomol. 35, 521-526.

Tälleklint-Eisen, L., and Lane, R. S. (1999). Variation in the density of questing Ixodes pacificus (Acari: Ixodidae) nymphs infected with Borrelia burgdorferi at different spatial scales in California. J. Parasitol. 49, 824-831. doi: $10.2307 / 3285817$

Tälleklint-Eisen, L., and Lane, R. S. (2000a). Spatial and temporal variation in the density of Ixodes pacificus (Acari: Ixodidae) nymphs. Environ. Entomol. 29, 272-280.

Tälleklint-Eisen, L., and Lane, R. S. (2000b). Efficiency of drag sampling for estimating population sizes of Ixodes pacificus 
(Acari: Ixodidae) nymphs in leaf litter. J. Med. Entomol. 37, 484-487.

Thornton, P. E., Hasenauer, H., and White, M. A. (2000). Simultaneous estimation of daily solar radiation and humidity from observed temperature and precipitation: an application over complex terrain in Austria. Agric. For. Meteorol. 104, 255-271. doi: 10.1016/S01681923(00)00170-2

Tyre, A. J., Bull, C. M., Tenhumberg, B., and Chilton, N. (2003). Indirect evidence of density-dependent population regulation in Aponomma hydrosauri (Acari: Ixodidae), an ectoparasite of reptiles. Austral Ecol. 28, 196-203. doi: 10.1046/j.14429993.2003.01270.x

Ueti, M. W., Reagan, J. O. Jr., Knowles, D. P. Jr., Scoles, G. A., Shkap, V., and Palmer, G. H. (2007). Identification of midgut and salivary glands as specific and distinct barriers to efficient tick-borne transmission of Anaplasma marginale.
Infect. Immun. 75, 2959-2964. doi: 10.1128/IAI.00284-07

Vial, L. (2009). Biological and ecological characteristics of soft ticks (Ixodida: Argasidae) and their impact for predicting tick and associated disease distribution. Parasite 16, 191-202. doi: 10.1051/parasite/2009163191

Wägele, H., Klussmann-Kolb, A., Kuhlmann, M., Haszprunar, G., Lindberg, D., Koch, A., et al. (2011). The taxonomist - an endangered race. A practical proposal for its survival. Front. Zool. 8:25. doi: 10.1186/1742-9994-8-25

Walker, J. B., Keirans, J. E., and Horak, I. G. (2000). The Genus Rhipicephalus (Acari, Ixodidae): A Guide to the Brown Ticks of the World. Cambridge: Cambridge University Press. doi: 10.1017/CBO9780511661754

Wickramasekara, S., Bunikis, J., Wysocki, V., and Barbour, A. G. (2008). Identification of residual blood proteins in ticks by mass spectrometry proteomics. Emerg. Infect. Dis. 14, 1273-1275. doi: 10.3201/eid1408.080227

Wilson, M. L. (1994). "Population ecology of tick vectors: interaction, measurement, and analysis," in Ecological Dynamics of Tick-Borne Zoonoses, eds D. E. Sonenshine and T. N. Mather (New York, NY: Oxford University Press), 20-44.

Wilson, M. L. (1998). Distribution and abundance of Ixodes scapularis (Acari: Ixodidae) in North America: ecological processes and spatial analysis. J. Med. Entomol. 35, 446-457.

Yssouf, A., Flaudrops, C., Drali, R., Kernif, T., Socolovschi, C., Berenger, J. M., et al. (2013). Matrix-assisted laser desorption ionization-time of flight mass spectrometry for rapid identification of tick vectors. J. Clin. Microbiol. 51, 522-528. doi: 10.1128/JCM.02665-12

Conflict of Interest Statement: The authors declare that the research was conducted in the absence of any commercial or financial relationships that could be construed as a potential conflict of interest.

Received: 02 June 2013; accepted: 17 July 2013; published online: 08 August 2013. Citation: Estrada-Peña A, Gray JS, Kahl $O$, Lane RS and Nijhof AM (2013) Research on the ecology of ticks and tick-borne pathogens-methodological principles and caveats. Front. Cell. Infect. Microbiol. 3:29. doi: 10.3389/ fcimb.2013.00029

Copyright (c) 2013 Estrada-Peña, Gray, Kahl, Lane and Nijhof. This is an openaccess article distributed under the terms of the Creative Commons Attribution License (CC BY). The use, distribution or reproduction in other forums is permitted, provided the original author(s) or licensor are credited and that the original publication in this journal is cited, in accordance with accepted academic practice. No use, distribution or reproduction is permitted which does not comply with these terms. 